\title{
THE EFFECT OF INTRAMOLECULAR H-BOND INTERACTIONS IN THE ISOMERIZATION PROCESS IN AMINO ACIDS
}

\author{
SELVARENGAN PARANTHAMAN*
}

\author{
Department of Physics and International Research Centre, Kalasalingam University, Krishnankoil - 626 126, INDIA
}

\section{ABSTRACT}

The effect of intramolecular hydrogen bond (H-bond) interactions in the cis - trans isomerization of the amino acids such as, cysteine, serine, threonine and valine have been studied using density functional theory method. Our calculations have shown that the geometrical parameters are significantly changed during the isomerization process. This is due to the presence of intramolecular H-bonds within main chain or in between side chain and main chain. The barrier energies have been calculated for isomerization process in all the amino acids, which is more for cysteine and less for valine. The Fourier decomposition potential has been obtained for the above named amino acids which show that $\mathrm{V}_{2}$ potential has higher value. The vibrational frequency analysis has been carried out for the cis and trans forms of cysteine, serine, threonine and valine amino acids and the results are discussed.

Keywords: cis-trans isomerization, H-bonds, barrier energy, amino acids, Fourier decomposition potential, density functional theory

\section{INTRODUCTION:}

The carboxylic group of amino acids has received more attention for the conformational analysis, because it is one of the basic constituent in amino acids. Earlier studies on neutral amino acids have shown that the conformations were affected by the presence of various intramolecular hydrogen bonding (H-bond) interactions and isomerization energy of the carboxylic group.[1-7] Rankin et al. have observed that the existence of intramolecular H-bonds might increase the chemical transformations rate.[8] The experimental data on this type of $\mathrm{H}$-bond is scarce, so theoretical studies can play an important role to determine the characteristic values for the intramolecular $\mathrm{H}$-bond. [9] In general, the intraand intermolecular H-bonds are similar in nature, however, the later has been studied extensively by supermolecular approach for the different chemical systems.[10] Further, this approach cannot be extended to the intramolecular bonds and so the energetic conformational analysis is one of the methods to study the above problem.[11-14] The other method for instance, isodesmic reactions leading to bond breaking and formation may also be used for the study of intramolecular H-bond interaction. However, still defining H-bond is a challenging problem in theoretical chemistry.[15] Because the description of $\mathrm{H}$-bond by theoretical methods is a difficult task. There are few computational studies were reported in the literature for the study of intramolecular H-bonded systems.[16,17]

Additionally, the cis-trans isomerization in amino acids plays a distinguished role in the proton transfer reaction of amino acid.[18] The studies on cis-trans isomerization were started in the second half of the $20^{\text {th }}$ century. Earlier it was noted that the amide nitrogen protonation causes the conversion to free rotation from hindered rotation of the N-protonated peptide bond.[19] Therefore, the carboxylic functional group is not only important for the conformational analysis and it plays a significant role in the tautomerization process also. Most of the earlier theoretical studies were mainly focused on the conformations of the amino acids and the isomerization study of this kind lacks the importance. Earlier, Tunon et al. reported that after the formation of neutral form from the zwitterionic form in the tautomerization process, a transformation takes place from the trans to cis form.[19] This is due to the low stability of trans form than the cis form. Further, the study on glycine by tortonda et al. showed that conformer Ip is more stable than conformer IIp in gas phase, whereas in solution, Glycine IIp is favoured by $\sim 3 \mathrm{kcal} / \mathrm{mol}$ at MP2 $/ 6-31+\mathrm{G}^{* *}$ level of theory, because of its higher dipole moment.[20] This indicates that glycine IIp easily undergoes zwitterionic form rather than Ip form and this can be confirmed by our earlier studies also.[21] In addition, it is interesting to study this transformation in amino acids, because some amino acids have cis form is more stable than the trans form and vice versa. Perczel once reported that side chain group determines the conformations of some peptides. [22] Hence, it is also necessary to study the effect of intramolecular interaction formed between side chain and $-\mathrm{COOH}$ group during the isomerization process. In our study, we have selected amino acids cysteine, serine, threonine and valine to study the effect of intramolecular H-bond interactions in cis-trans isomerization. These amino acids are classified as polar (cysteine, serine, and threonine) and nonpolar (valine) amino acid, and each of these having some special importance in their conformational energetic.[23-30] The cysteine molecule with trans form of the carboxylic group is more stable than cis form, but, other amino acids having cis form is the most stable form in gas phase. In addition, the reason for the selection of these amino acids is that they have received considerable attention among experimental and theoretical scientists, because of their biological significance.

In the past few decades theoretical methods have played as a major tool to study the physical and chemical properties of various atomic and molecular systems. These methods have acted as alternate to high cost experimental techniques. Theoretical methods have been differentiated as classical and quantum mechanical methods. In general, classical methods such as Monte Carlo and molecular dynamics were mainly used for larger molecular systems. Similarly, quantum mechanical methods were used for smaller systems ranges few 10 s of atoms. Researchers mostly use ab initio methods to study the $\mathrm{H}$-bonded biological systems, because of its accuracy in predicting H-bond energy within the error range $1 \mathrm{kcal} / \mathrm{mol} .[31,32]$ However, the ab initio methods such as MP2, CCSD, etc are computationally very expensive. One needs to find out less expensive computational method for the studies on H-bonded systems. In the past two decades, density functional theory (DFT) methods have played important role in studying atomic and molecular systems. It can be used as an alternate to high cost experimental and computational techniques. Hence, in the present investigation, DFT method is used to study the preferences of conformations between cis and trans forms in the cis-trans isomerization process and the effect of intramolecular H-bond exist in the amino acids cysteine, serine, threonine, and valine. Fourier decomposition analysis has been performed for the potential function for the formation of trans form from cis form. Finally, the vibrational frequency analysis has been carried out to analyze the cis-trans conformers.

Computational details:

The DFT method is used to study the cis and trans conformers of cysteine, serine, threonine, and valine amino acids. The selection of DFT functional for the studies on H-bonded systems is a difficult task. One must be careful for the selection of DFT functional for the studies on H-bonded systems. Because, many number of DFT functionals available recently, which ranges from local density approximation (LDA) to hybrid meta generalized gradient approximation (hybrid meta-GGA) methods. In order to study H-bonded systems by DFT functional, the functional must contain dispersion term. In $\mathrm{H}$-bond dispersion forces play important role. There is a significant difference in energy values, calculated by the functional with and without dispersion term. In our study we have selected Becke's three parameter exact exchange functional (B3) [33] combined with gradient corrected correlation functional of Lee-Yang-Parr (LYP) [34]. Our earlier study [35] has shown that, this functional produces reasonable result for the studies on H-bonded systems. In order to avoid the basis set to affect the relative energy, the calculations have been performed using higher $6-311++\mathrm{G}^{* *}$ basis set. To study the cis-trans isomerization of the amino acids, the potential energy surface scan have been employed for the cis conformer of the amino acids in B3LYP/6-311++G** level of theory. The torsional angle $\omega(\mathrm{OCOH})$ is varied in steps of $30^{\circ}$ between $\omega=0^{\circ}$ (cis) and $\omega=180^{\circ}$ (trans) in both the direction (clockwise, and counterclockwise), to 
predict the influence of side chain in the potential energy of each amino acid. The six-term truncated fourier expansion [36] is considered for the potential function, $V(\omega)$ as

$V(\omega)$ is the relative energy at the rotational angle $\omega$. All the calculations were performed using Gaussian 09W program package.[37]

$$
V(\varpi)=\sum_{i=1}^{6} \frac{1}{2} V_{i}(1-\cos (i \varpi))
$$

\section{RESULTS AND DISCUSSION}

The cis and trans forms of the amino acids cysteine, serine, threonine, and valine have been optimized at B3LYP functional. The selected main chain structural parameters are presented in Table 1 along with relative energy values. Fig. 1. shows the optimized cis and trans form of the amino acids, cysteine, serine, threonine, and valine. In the present study, the isomerization path of the most stable form for cysteine, serine, threonine, and valine amino acids have been investigated.

(a)

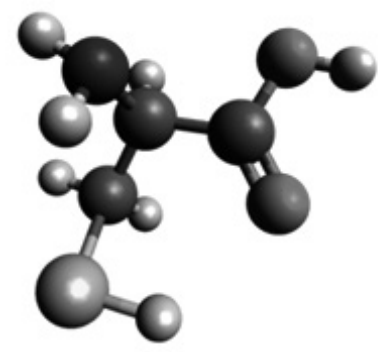

(c)

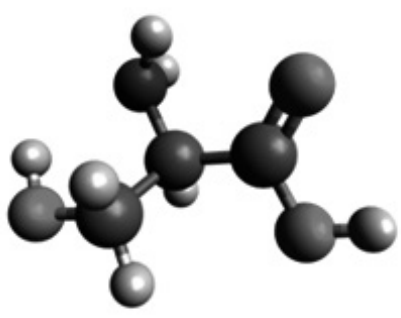

(e)

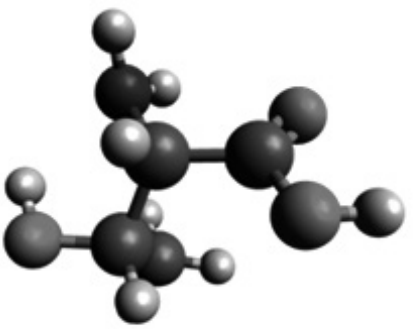

(g)

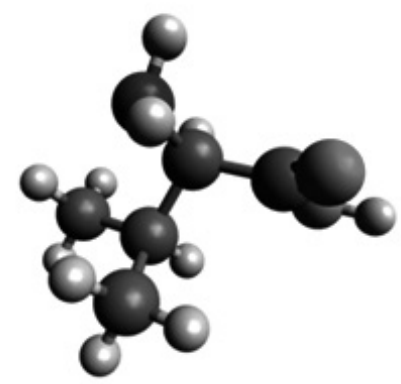

(b)

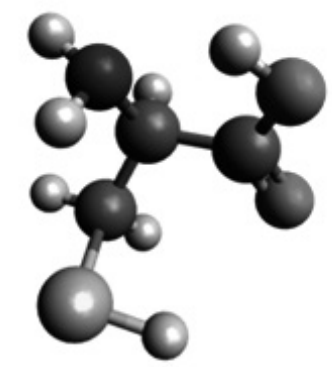

(d)

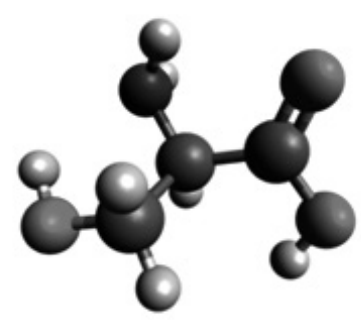

(f)

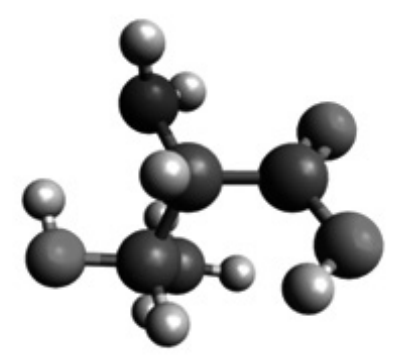

(h)

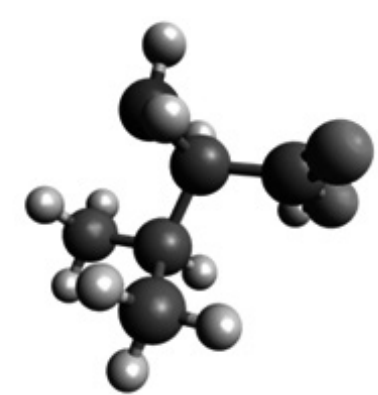

Fig.1. Optimized cis (a, c, e, g) and trans (b, d, f, h) forms of amino acids cysteine, serine, threonine, and valine. (Atom colour: Grey $=$ Carbon, White $=$ Hydrogen, Red $=$ Oxygen, Blue $=$ Nitrogen, and Yellow=Sulfur). 
Table 1 Selected geometrical parameters and relative energies $(\Delta \mathrm{E}, \mathrm{kcal} / \mathrm{mol}$.) of cis and trans forms of cysteine, serine, threonine and valine calculated using B3LYP/6-311++G** level of theory

\begin{tabular}{|c|c|c|c|c|c|c|c|c|}
\hline \multirow{2}{*}{ Parameters } & \multicolumn{2}{|c|}{ cysteine } & \multicolumn{2}{c|}{ serine } & \multicolumn{2}{c|}{ threonine } & \multicolumn{2}{c|}{ Valine } \\
\cline { 2 - 9 } & Cis & Trans & Cis & Trans & Cis & Trans & Cis & Trans \\
\hline $\mathrm{C}-\mathrm{N}$ & 1.461 & 1.467 & 1.459 & 1.458 & 1.459 & 1.458 & 1.457 & 1.456 \\
\hline $\mathrm{C}-\mathrm{C}$ & 0.532 & 1.547 & 1.524 & 1.535 & 1.523 & 1.534 & 1.530 & 1.542 \\
\hline $\mathrm{C}=\mathrm{O}$ & 1.208 & 1.207 & 1.206 & 1.199 & 1.206 & 1.200 & 1.206 & 1.200 \\
\hline $\mathrm{C}-\mathrm{O}$ & 1.348 & 1.337 & 1.353 & 1.358 & 1.353 & 1.359 & 1.356 & 1.361 \\
\hline $\mathrm{O}-\mathrm{H}$ & 0.970 & 0.983 & 0.970 & 0.966 & 0.970 & 0.966 & 0.970 & 0.965 \\
\hline$\angle \mathrm{NCCO}$ & -77.59 & -18.28 & -167.40 & -165.73 & 169.83 & 169.79 & -164.36 & -167.07 \\
\hline$\angle \mathrm{OCOH}$ & -3.45 & -176.62 & 0.73 & -178.11 & -0.53 & 179.15 & 0.91 & 179.67 \\
\hline$\Delta \mathrm{E}$ & 4.38 & 0.00 & 0.00 & 5.70 & 0.00 & 5.42 & 0.00 & 5.41 \\
\hline
\end{tabular}

From the calculated results it has been observed, that there are the significant changes in the geometrical and energetical parameters of all the amino acids considered in this study. The trans conformer of cysteine contains an $\mathrm{H}-\mathrm{N}$...H-O intramolecular H-bond which is more stable than cis form by $4.38 \mathrm{kcal} / \mathrm{mol}$. The calculated backbone torsional angle (NCCO) for cis and trans conformers of cysteine are $-77.59^{\circ}$ and $-18.28^{\circ}$ respectively. This indicates that trans form is more planar than cis form. The hydroxyl group should be rotated into clockwise or counterclockwise direction, to understand isomerization process from the cis to the trans conformer. During the counterclockwise rotation the transition state exists at $\omega=-90^{\circ}$, lying 11.26 $\mathrm{kcal} / \mathrm{mol}$. more than cis conformer. In the clockwise rotation of the carboxylic group at $\omega=90^{\circ}$ gives the transition state, which is $15.07 \mathrm{kcal} / \mathrm{mol}$. higher than cis conformer. The energy difference between clockwise and counterclockwise direction at the transition state is $\sim 3.5 \mathrm{kcal} / \mathrm{mol}$. Earlier study by FernandezRamos et al. [27] have noted that, there is a change in the order of conformation stability when they used Hartree-Fock method. In addition, the intramolecular $\mathrm{H}$-bond $-\mathrm{SH}$...OC exists in cysteine cis form. During the isomerization, the backbone torsion angle is reduced to $-18.28^{\circ}$, which disable the $-\mathrm{SH}$... OC interaction in cysteine trans form. Moreover, the geometrical parameters of cysteine are significantly changed during the isomerization. The calculated $\mathrm{C}-\mathrm{N}$ bond length increases $(\sim 0.006 \AA)$ along with $\mathrm{C}-\mathrm{C}$ and $\mathrm{O}-\mathrm{H}$ bonds. This indicates the formation of $\mathrm{H}$-bond in the main chain. During the formation of $\mathrm{H}$-bond, the lone pair electrons of nitrogen atom attracts more charges from the nearest neighbour, leads to elongate the $\mathrm{C}-\mathrm{N}, \mathrm{C}-\mathrm{C}$ and $\mathrm{O}-\mathrm{H}$ bonds. However, the $\mathrm{C}-\mathrm{O}$ bond shortens due to the absence of interaction $-\mathrm{SH}$... OC in the trans form. It was noted by earlier study on substituted proline pointed the presence of an NH...N intramolecular H-bond, induces the amide isomerization.[38]

In serine, the intramolecular H-bond exists between amino and hydroxyl groups of side chain in both cis and trans conformer. This is confirmed with earlier study by Dokmaisrijan et al. [39]. They have also observed intramolecular $\mathrm{H}$-bond between amino and hydroxyl groups in the most stable conformer. They have performed the calculations using high level ab initio method. In our study, the cis conformer is energetically more stable $5.70 \mathrm{kcal} /$ mol. than trans conformer. The transition state exists at $\omega=90^{\circ}$ and $\omega=-90^{\circ}$ lying energy $14.24,13.94 \mathrm{kcal} / \mathrm{mol}$. respectively. The external forces (intramolecular $\mathrm{H}$-bond) do not perturb the potential function of $-\mathrm{OH}$ group during the isomerization process in both clockwise and counterclockwise direction. While considering the geometrical parameters, the bonds $\mathrm{C}-\mathrm{C}, \mathrm{C}-\mathrm{O}$ elongate and the bonds $\mathrm{C}=\mathrm{O}$, O-H shorten $(\sim 0.005 \AA)$. No change in the $\mathrm{C}-\mathrm{N}$ bond length has been observed, this is due to the intramolecular interaction which stabilizes the $\mathrm{C}-\mathrm{N}$ bond during the isomerization.

In threonine, the intramolecular interaction exists between the $\mathrm{N}$-terminal and side chain $-\mathrm{OH}$ group. The cis form is energetically more stable than trans form, which is about $5.42 \mathrm{kcal} / \mathrm{mol}$. The transition state exists at $\omega=90^{\circ}(13.77$ $\mathrm{kcal} / \mathrm{mol})$ and $\omega=-90^{\circ}(13.99 \mathrm{kcal} / \mathrm{mol}$.) for clockwise and counterclockwise direction. This indicates that, the isomerization process is similar in both directions. It is observed that there is no significant difference in energy between clockwise and counterclockwise direction. Further, the structural parameters of threonine are similar to serine, the addition of methyl group in the side chain is not affected much in the main chain structural parameters of threonine. In the case for valine, the cis form is more stable $(5.41 \mathrm{kcal} / \mathrm{mol}$.) than trans form. However, the transition state exists at $\omega=90^{\circ}$ and $\omega=-90^{\circ}$, the energy is $13.84,13.78 \mathrm{kcal} / \mathrm{mol}$ for clockwise and counterclockwise direction respectively. In comparison with serine and threonine, valine has similar changes in the structural parameters of backbone atoms. The addition of one more methyl group in the place of $-\mathrm{OH}$ group slightly change the structural parameters. The C-C bond length in the cis form of threonine is $1.523 \AA$, and the same in cis valine is $1.530 \AA$.

The barrier energy has been calculated using B3LYP functional for the considered amino acids and the results are given in Table 2 . Barriers to internal rotation about $\mathrm{C}-\mathrm{O}$ single bonds adjacent to $\mathrm{C}=\mathrm{O}, \mathrm{C}-\mathrm{C}$ groups have been studied here. The maximum energy was obtained at $\omega=90^{\circ}$ and $-90^{\circ}$ for all the amino acids. The barrier height is comparably different for different amino acids and it is higher for cysteine and low for other amino acids. Serine is having second highest reaction barrier. On the other hand, valine has very low barrier, which indicates that formation of trans form is easily possible in this amino acid. There is no intramolecular interaction or weak interaction in the isomerization path of valine. Further, not much variation is observed in the barrier of serine, threonine, and valine amino acids for clockwise and counterclockwise direction. The barrier is high in serine and valine for the clockwise direction, whereas in threonine it is for counterclockwise direction. The energy barrier in cysteine is higher than other amino acids. The reason behind this is, in cysteine at $\omega=90^{\circ}$, there is a repulsive interaction takes place between bonding orbitals of $\mathrm{C}-\mathrm{H}$ and $\mathrm{O}-\mathrm{H}$ group, so the barrier is comparably high in this direction. Moreover, when the hydrogen turned to $-90^{\circ}$, the nitrogen strongly attract the hydrogen atom and form the intramolecular H-bond. Additionally another interaction may be possible between the sulfur and hydrogen in carboxyl only single full stop applicable. Thus, the intramolecular H-bonds catalyze the isomerization reaction in cysteine, but no such effect is observed in other amino acids.

The six-term torsional potential function for the cysteine, serine, threonine, and valine are computed at B3LYP functional and are given in Table 3. The rotation of $\mathrm{C}-\mathrm{O}$ bond in both directions in these amino acids shows that $\mathrm{V}_{2}$ term has maximum value, which indicates that the structure is having twofold barrier. The $\mathrm{V}_{2}$ value is larger for cysteine molecule. This may be due to the repulsive interaction between $-\mathrm{CH}_{2}$ and $-\mathrm{COH}$ groups. In cysteine, trans form is more stable than cis form, this is due to the H-bond interaction between the nitrogen atom in amino group and hydrogen in carboxylic group. The contribution of $\mathrm{V}$, term is more in cysteine, serine, and threonine but in valine, it is found to be lower than other potential terms. In cysteine clockwise $\mathrm{V}_{2}$ potential is higher than counterclockwise $\mathrm{V}_{2}$ potential, which is $12.34,9.00$ respectively. It is comparable with earlier studies of $\mathrm{C}-\mathrm{O}$ bond internal rotation in glycine and alanine amino acids.[35]

The selected harmonic vibrational frequencies and IR intensities of the cis and trans forms of amino acids, cysteine, serine, threonine and valine are given in Table 4 . In order to study the changes in the frequencies, the cis form is kept as a reference for all the amino acids. When considering cysteine, most of the frequencies are shifted during the isomerization due to the existence of different intramolecular H-bond interaction in this system. In the trans form of cysteine, the intramolecular interaction exists between the amino and carboxyl group. Due to this, the $\mathrm{OH}$ stretching frequency down shifted $\left(\sim 200 \mathrm{~cm}^{-1}\right)$ which indicates the elongation of $\mathrm{O}-\mathrm{H}$ bond. During the formation of trans form, the torsional rotation in $\mathrm{C}-\mathrm{C}$ bond of main chain is also noted. From the frequency values of cis and trans form of cysteine, one can clearly study the isomerization process. The main chain $\mathrm{C}-\mathrm{C}$ bond elongate as the frequency decreases and the side chain $\mathrm{C}-\mathrm{C}$ bond shortens for cysteine. The $\mathrm{CCO}$ bend, $\mathrm{OH}$ torsion, and $\mathrm{NH}_{2}$ asymmetric stretch frequencies are blue shifted to different extent while the isomerization takes place in cysteine. While studying the serine, the $\mathrm{C}-\mathrm{O}$ stretching frequency downshifted $\left(16 \mathrm{~cm}^{-1}\right)$ for the isomerization. The $\mathrm{OH}$ 
bending frequency is also red shifted and the intensity is high $(232.4 \mathrm{Km} / \mathrm{mol}$.) in the trans form. The $\mathrm{C}=\mathrm{O}$ and $\mathrm{OH}$ stretching frequencies, are blue shifted, while the intramolecular $\mathrm{H}$-bond takes place between the $\mathrm{N}-\mathrm{H}$ and $\mathrm{C}=\mathrm{O}$ group where as the $\mathrm{O}-\mathrm{H}$ bond shorten in the trans form. Moreover, the $\mathrm{CH}$ stretching frequency is down shifted from 3072 to $3037 \mathrm{~cm}^{-1}$. For the case of threonine, $\mathrm{CCO}$ bending frequency, $\mathrm{CCC}$ bending frequency, $\mathrm{C}=\mathrm{O}$ bending and $\mathrm{NCC}$ bending, $\mathrm{OH}$ bending and $\mathrm{CH}$ bending, stretching frequencies are found to be down shifted, as well as $\mathrm{C}=\mathrm{O}$ stretching and $\mathrm{OH}$ stretching are found to be upshifted. This indicates that the trans form is less stable than the cis form. In summary, we have noted that the most of the frequencies are shifted due to the formation of intramolecular interactions.

As mentioned earlier, description of H-bond energy by the DFT is a difficult task. In general, the presence of H-bond interactions affects the conformational stability of amino acids. This has been extensively studied in the literature. Further, the validity of DFT functionals for the studies on amino acids, (H-bonded systems) have also been well studied.[35] The scope of the present study is not related with neither DFT assessment studies on H-bonded systems or difficult description of H-bonded systems by DFT methods. However, our calculations have been performed with most reliable and widely used DFT method (B3LYP/6-311++G**). Our study shows that the presence of intramolecular H-bond interactions affects the cis-trans isomerization process in amino acids. There is a significant difference in energy values between clockwise and counterclockwise direction of isomerization process in cysteine. This is due to the presence of intramolecular H-bond between main chain and side chain in the amino acid.

Table 2 Relative energies (in $\mathrm{kcal} / \mathrm{mol}$ ) for cis-trans isomerization path of cysteine, serine, threonine, and valine calculated at B3LYP/6-311++G** level of theory.

\begin{tabular}{|c|c|c|c|c|c|c|c|c|}
\hline \multirow{2}{*}{ Parameters } & \multicolumn{2}{|c|}{ cysteine } & \multicolumn{2}{|c|}{ serine } & \multicolumn{2}{|c|}{ threonine } & \multicolumn{2}{|c|}{ valine } \\
\hline & Clockwise & anticlockwise & Clockwise & anticlockwise & Clockwise & anticlockwise & Clockwise & anticlockwise \\
\hline 0 & 0 & 0.00 & 0.00 & 0.00 & 0.00 & 0.00 & 6.49 & 6.49 \\
\hline 30 & 3.84 & 2.37 & 3.01 & 3.26 & 3.40 & 2.85 & 8.15 & 8.41 \\
\hline 60 & 10.88 & 8.22 & 9.72 & 9.87 & 9.96 & 9.46 & 12.10 & 12.49 \\
\hline 90 & 15.07 & 11.26 & 14.24 & 13.94 & 13.77 & 13.99 & 13.84 & 13.78 \\
\hline 120 & 13.11 & 8.34 & 12.96 & 12.29 & 11.95 & 12.87 & 9.94 & 9.36 \\
\hline 150 & 8.30 & 4.73 & 8.92 & 8.35 & 8.05 & 8.71 & 3.38 & 2.83 \\
\hline 180 & 4.96 & 4.96 & 6.85 & 6.85 & 6.56 & 6.56 & 0.00 & 0.00 \\
\hline
\end{tabular}

Values in bold are barrier energies.

Table 3 Fourier decomposition potential of cis-trans isomerization of cysteine, serine, threonine, and valine calculated at B3LYP/6-311++G** level of theory.

\begin{tabular}{|c|c|c|c|c|c|c|c|c|}
\hline \multirow{2}{*}{ Potentials } & \multicolumn{2}{|c|}{ cysteine } & \multicolumn{2}{|c|}{ serine } & \multicolumn{2}{|c|}{ threonine } & \multicolumn{2}{|c|}{ valine } \\
\hline & Clockwise & anticlockwise & Clockwise & anticlockwise & Clockwise & anticlockwise & Clockwise & anticlockwise \\
\hline $\mathrm{V}_{1}$ & 4.973 & 3.043 & 6.773 & 6.011 & 5.535 & 6.706 & -3.505 & -4.267 \\
\hline $\mathrm{V}_{2}$ & 12.342 & 9.003 & 10.793 & 10.500 & 10.467 & 10.667 & 12.733 & 12.633 \\
\hline $\mathrm{V}_{3}$ & 0.163 & 1.577 & 0.117 & 0.667 & 0.860 & -0.100 & 1.467 & 2.067 \\
\hline $\mathrm{V}_{4}$ & 0.349 & -1.270 & -0.247 & -0.367 & -0.247 & -0.200 & 1.933 & 1.833 \\
\hline $\mathrm{V}_{5}$ & -0.179 & 0.330 & -0.040 & 0.122 & 0.165 & -0.106 & 2.038 & 2.200 \\
\hline $\mathrm{V}_{6}$ & 0.245 & -0.228 & 0.022 & 0.000 & 0.013 & -0.017 & 1.067 & 1.067 \\
\hline
\end{tabular}

\section{CONCLUSIONS}

The cis-trans isomerization of amino acids cysteine, serine, threonine, and valine has been studied using DFT-B3LYP method. From the results, it can be observed that the geometrical parameters are significantly changed during the isomerization process, which is more for cysteine. The barrier energies are considerably different for different amino acids, and it is higher for cysteine and lower for valine. This indicates that the formation of trans form is easily possible in valine. Further, the presence of intramolecular H-bonds catalyzes the isomerization reaction in cysteine, but no such effect is observed in other amino acids. The barrier is two fold in all the amino acids. From the vibrational frequencies analysis it has been noted that most of the frequencies are shifted due to the presence of intramolecular interaction. Thus, the presence of intramolecular $\mathrm{H}$-bonds in cysteine produces significant structural and energetical changes during the isomerization process. No such effect is observed in other amino acids. Our study demonstrates the effect of $\mathrm{H}$-bonding interactions in the cis-trans isomerization of amino acids. We believe that our present study will be helpful to experimentalists and computational chemists for further studies on intramolecular H-bond interactions in biological systems. 


\begin{tabular}{|c|c|c|c|c|c|c|c|c|c|c|c|c|c|c|c|c|c|c|c|c|}
\hline \multirow{3}{*}{ 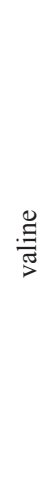 } & 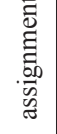 & $\begin{array}{l}0 \\
\bar{z} \\
0 \\
0 \\
0 \\
0\end{array}$ & \begin{tabular}{|l}
$\tilde{Z}$ \\
$\tilde{D}$ \\
0 \\
$\tilde{J}$ \\
\end{tabular} & $\begin{array}{l}\text { th } \\
0 \\
0 \\
0\end{array}$ & $\begin{array}{l}y \\
y \\
\text { E }\end{array}$ & 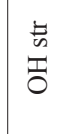 & & & & & & & & & & & & & & \\
\hline & 鸪 & 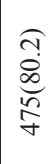 & 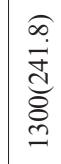 & $\begin{array}{l}\widehat{m} \\
\infty \\
\infty \\
\tilde{d} \\
\tilde{\infty} \\
\infty \\
-\end{array}$ & 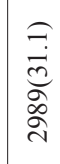 & 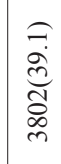 & & & & & & & & & & & & & & \\
\hline & $\frac{\infty}{0}$ & 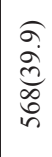 & 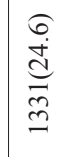 & 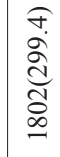 & 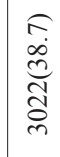 & $\begin{array}{l}\frac{n}{n} \\
\vec{b} \\
\tilde{n} \\
\tilde{n}\end{array}$ & & & & & & & & & & & & & & \\
\hline \multirow{3}{*}{ 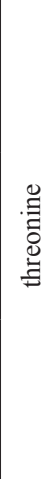 } & 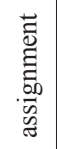 & 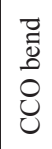 & $\begin{array}{l}\tilde{z} \\
\overline{\tilde{J}} \\
\underline{\tilde{J}} \\
\tilde{U}\end{array}$ & $\begin{array}{l}\tilde{z} \\
\tilde{D} \\
0 \\
0 \\
0 \\
0\end{array}$ & $\begin{array}{l}\tilde{J} \\
\tilde{J} \\
\text { D. } \\
0\end{array}$ & $\begin{array}{l}\text { th } \\
0 \\
0 \\
0\end{array}$ & $\begin{array}{l}\text { E } \\
\text { J } \\
\text { D. }\end{array}$ & $\begin{array}{l}\text { E } \\
\text { J }\end{array}$ & a & & & & & & & & & & & \\
\hline & $\begin{array}{l}\text { 气 } \\
\text { 蛋 }\end{array}$ & 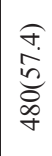 & 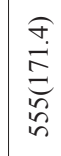 & 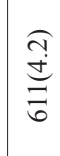 & $\begin{array}{l}\tilde{n} \\
\infty \\
n \\
2 \\
0 \\
0 \\
n\end{array}$ & $\begin{array}{l}\widehat{\infty} \\
\dot{d} \\
\stackrel{d}{d} \\
\tilde{\infty} \\
-\end{array}$ & 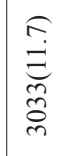 & 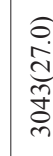 & 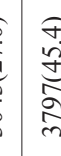 & & & & & & & & & & & \\
\hline & $\stackrel{\infty}{0}$ & 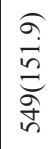 & 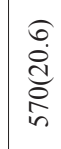 & \begin{tabular}{l}
$\widehat{\tau}$ \\
$\infty$ \\
$\tilde{f}$ \\
\multirow{f}{0}{}
\end{tabular} & 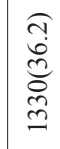 & 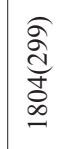 & 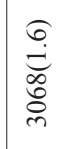 & $\begin{array}{l}7 \\
0 \\
0 \\
0 \\
0\end{array}$ & 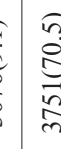 & & & & & & & & & & & \\
\hline \multirow{3}{*}{ 竞 } & 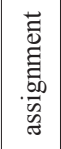 & $\begin{array}{l}b \\
0 \\
0 \\
0 \\
0\end{array}$ & 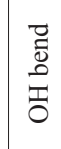 & $\begin{array}{l} \pm \\
5 \\
0 \\
0 \\
0\end{array}$ & $\begin{array}{l}\bar{E} \\
E \\
E\end{array}$ & 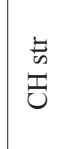 & $\begin{array}{l}\frac{n}{5} \\
\text { I }\end{array}$ & & & & & & & & & & & & & \\
\hline & $\begin{array}{l}\text { है } \\
\text { E् }\end{array}$ & 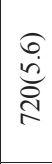 & 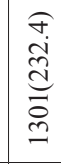 & $\begin{array}{l}\sigma \\
\mathbb{0} \\
\tilde{D} \\
\mathbb{d} \\
\infty \\
\infty \\
\infty \\
-\end{array}$ & 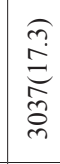 & 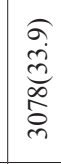 & 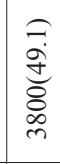 & & & & & & & & & & & & & \\
\hline & $\frac{n}{0}$ & 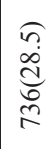 & 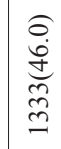 & 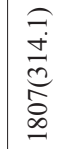 & 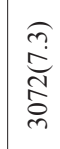 & $\begin{array}{l}\sigma \\
0 \\
0 \\
\tilde{D} \\
0 \\
m\end{array}$ & 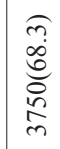 & & & & & & & & & & & & & \\
\hline \multirow{3}{*}{ 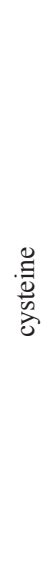 } & 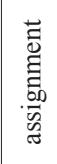 & $\begin{array}{l}\stackrel{5}{0} \\
0 \\
0\end{array}$ & 总 & $\begin{array}{l}\breve{s} \\
0 \\
0\end{array}$ & $\begin{array}{l}\tilde{z} \\
\tilde{D} \\
\tilde{D} \\
\tilde{Z} \\
z\end{array}$ & $\begin{array}{l}\bar{z} \\
\overline{0} \\
0 \\
0 \\
0 \\
0\end{array}$ & $\begin{array}{l}\vec{z} \\
\tilde{D} \\
0 \\
0 \\
ن \\
0\end{array}$ & 总 & $\begin{array}{l}0 \\
\overline{0} \\
0 \\
0 \\
0\end{array}$ & & 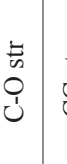 & $\begin{array}{l} \pm \\
5 \\
0 \\
0\end{array}$ & $\begin{array}{l}\vec{z} \\
\bar{D} \\
\vec{D} \\
\vec{z}\end{array}$ & $\begin{array}{l}n \\
b \\
0 \\
0\end{array}$ & $\begin{array}{l}\bar{n} \\
\bar{b} \\
z\end{array}$ & $\begin{array}{l}\vec{J} \\
\bar{J} \\
\vec{J}\end{array}$ & $\begin{array}{l}5 \\
0 \\
0 \\
0\end{array}$ & $\begin{array}{l}\vec{b} \\
\overrightarrow{0} \\
\vec{J}\end{array}$ & 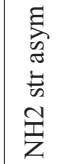 & 章 \\
\hline & 气 & 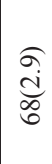 & 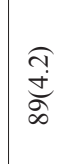 & 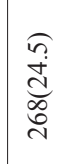 & 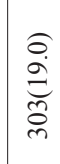 & 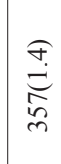 & 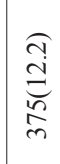 & ત્ર & $\begin{array}{l}\infty \\
0 \\
0 \\
0\end{array}$ & & 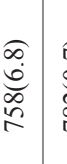 & 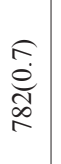 & 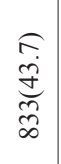 & 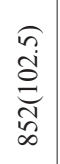 & 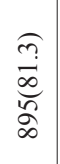 & 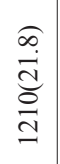 & 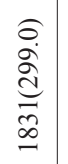 & 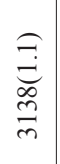 & 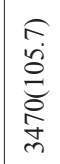 & 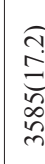 \\
\hline & $\frac{n}{0}$ & $\begin{array}{l}\text { f. } \\
\text { o. } \\
\text { d. }\end{array}$ & 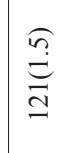 & 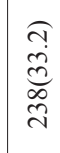 & 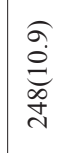 & 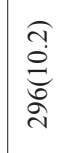 & 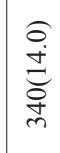 & 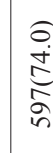 & $\left\{\begin{array}{l}\sigma \\
\infty \\
\infty \\
\infty \\
0 \\
0\end{array}\right.$ & & 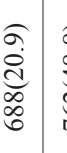 & 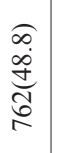 & 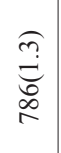 & $\begin{array}{l}\hat{\infty} \\
\stackrel{+}{\vec{t}} \\
\stackrel{0}{\infty}\end{array}$ & 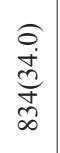 & $\begin{array}{l}0 \\
0 \\
0 \\
0 \\
=\end{array}$ & 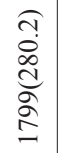 & 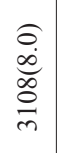 & 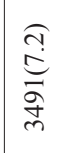 & $\begin{array}{c}\stackrel{f}{s} \\
\stackrel{5}{5} \\
\stackrel{f}{n} \\
\text {. }\end{array}$ \\
\hline$\dot{m}$ & & - & $N$ & $m$ & $\nabla$ & in & 6 & r & $\infty$ & & a & 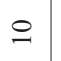 & $=$ & $\simeq$ & 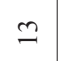 & \pm & 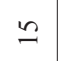 & 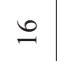 & $=$ & $\stackrel{\infty}{\infty}$ \\
\hline
\end{tabular}




\section{ACKNOWLEDGEMENT}

The author is thankful to the management of Kalasalingam University for providing the financial support to establish the computational research facility at the international research centre (IRC), Kalasalingam University. The author is thankful to Science and Engineering Research Board (SERB), Govt. of India, for the financial support in the form of the project (YSS/2015/001311).

\section{REFERENCES}

[1] A. G. Császár, J. Am. Chem. Soc. 114 (1992) 9568.

[2] C.H. Hu, M. Shen, H.F. Schaefer, J. Am. Chem. Soc. 115 (1993) 2923.

[3] A.G. Császár, J. Phys. Chem. 100 (1996) 3541.

[4] A.G. Császár, W.D. Allen, H.F. Schaefer III, J. Chem. Phys. 108 (1998) 9751

[5] A.G. Császár, A. Perczel, Prog. Biophys. Mol. Biol. 71(1999) 243.

[6] C.M. Jones, M. Bernier, E. Carson, K.E. Colyer, R. Metz, A. Pawlow, E.D. Wischow, I. Webb, E.J. Andriole, J.C. Poutsma, Int. J. Mass Spectrom. 267 (2007) 54.

[7] Q. Ashton Acton, Aromatic Amino Acids - Advances in Research and Treatment, Scholarly Editions, 2013.

[8] K.N. Rankin, R.J. Boyd, J. Phys. Chem. A 106 (2002) 11168.

[9] S. Scheiner, Hydrogen bonding: A Theoretical Perspective, (Oxford University Press, New York, 1997).

[10]Z.T. Li, L.Z. Wu, Hydrogen Bonded Supramolecular Structures. (Springer Berlin Heidelberg, 2015)

[11] A. Kovacs, A. Szabo, I. Hargittai, Acc. Chem. Res. 35 (2002) 887.

[12] P. Lipkowski, A. Koll, A. Karpfen, P. Wolschann, Chem. Phys. Lett. 360 (2002) 256.

[13]E.G. Bakalbassis, A.T. Lithoxoidou, A.P. Vafiadis, J. Phys. Chem. A 107 (2003) 8594

[14]H.Y. Zhang, Y.M. Sun, X.L. Wang, Chem. Eur. J. 9 (2003) 502.

[15]E. Arunan, G.R. Desiraju, R.A. Klein, J. Sadlej, S. Scheiner, I. Alkorta, D.C. Clary, R.H. Crabtree, J.J. Dannenberg, P. Hobza, H.G. Kjaergaard, A.C. Legon, B. Mennucci, D.J. Nesbitt, Pure Appl. Chem. 88 (2011) 1619.

[16]M. M. Deshmukh, S. R. Gadre. J. Phys. Chem. A 113 (2009) 7927.

[17]K. Wendler, J. Thar, S. Zahn, B. Kirchner. J. Phys. Chem. A 114 (2010) 9529.

[18]F. Duarte, E. Vöhringer-Martinez, A. Toro-Labbé, Phys. Chem. Chem. Phys. 13 (2011) 7773.

[19]I. Tunon, E. Silla, M.F. Ruiz-Lopez, Chem. Phys. Lett. 321 (2000) 433.

[20]F.R. Tortonda, J.L. Pascual-Almir, E. Silla, F.J. Ramirez, J. Chem. Phys. 109 (1998) 592

[21]P. Selvarengan, P. Kolandaivel, J. Mol. Struct. (Theochem) 617 (2002) 99.

[22]A. Perczel, A.G. Császár, J. Comp. Chem. 21 (2000) 882.

[23]S. Gronert, R.A.J. O’ Hair. J. Am. Chem. Soc. 117 (1995) 2071

[24] S. Shirazian, S. Gronert, J. Mol. Struct. (Theochem) 397 (1997) 107.

[25]L Schafer, K. Siam, V.J. Klimkowski, J.D. Ewbank, C. Van Alsenoy, J. Mol. Struct. (Theochem) 204 (1990) 361.

[26] L. Schafer, S.Q. Kulp-Newton, K. Siam, V.J. Klimkowski, C. Van Alsenoy, J. Mol. Struct. (Theochem) 209 (1990) 373.

[27]A. Fernandez-Ramos, E. Cabaleiro-Lago, J.M. Hermida-Ramon, E. Martınez-Núnez, A. Pena-Gallego, J. Mol. Struct. (Theochem) 498 (2000) 191.

[28]B. Lambie, R. Ramaekers, G. Maes, G. J. Phys. Chem. A, 108 (2004) 10426.

[29]T. Szidarovszky, G. Czakó, A.G. Császár, Mol. Phys., 107 (2009) 761.

[30] S.G. Stepanian, I.D. Reva, E.D. Radchenko, L. Adamowicz, J. Phys. Chem. A, 103 (1999) 4404.

[31]J.E. Del Bene, Hydrogen bonding: 1. Encyclopedia of Computational Chemistry, John Wiley: Chichester, UK, 1998; Vo1. 2.

[32] J.E. Del Bene, M.J.T. Jordan, J. Mol. Struct. (Theochem), 573, (2001) 11

[33] A.D. Becke, J. Chem. Phys. 98 (1993) 5648.

[34] C. Lee, W. Yang, R.G. Parr, Phys. Rev. B, 37 (1988) 785

[35]P. Selvarengan, P. Kolandaivel, J. Mol. Struct. (Theochem) 671 (2004) 77

[36]L. Radom, J.A. Pople, J. Am. Chem. Soc. 92 (1970) 4786.

[37] Gaussian 09, Revision D.01, M. J. Frisch, G. W. Trucks, H. B. Schlegel, G. E. Scuseria, M. A. Robb, J. R. Cheeseman, G. Scalmani, V. Barone, B. Mennucci, G. A. Petersson, H. Nakatsuji, M. Caricato, X. Li, H. P. Hratchian, A. F. Izmaylov, J. Bloino, G. Zheng, J. L. Sonnenberg, M. Hada, M. Ehara, K. Toyota, R. Fukuda, J. Hasegawa, M. Ishida, T. Nakajima, Y. Honda, O. Kitao, H. Nakai, T. Vreven, J. A. Montgomery, Jr., J. E. Peralta, F. Ogliaro, M. Bearpark, J. J. Heyd, E. Brothers, K. N. Kudin,
V. N. Staroverov, R. Kobayashi, J. Normand, K. Raghavachari, A. Rendell, J. C. Burant, S. S. Iyengar, J. Tomasi, M. Cossi, N. Rega, J. M. Millam, M. Klene, J. E. Knox, J. B. Cross, V. Bakken, C. Adamo, J. Jaramillo, R. Gomperts, R. E. Stratmann, O. Yazyev, A. J. Austin, R. Cammi, C. Pomelli, J. W. Ochterski, R. L. Martin, K. Morokuma, V. G. Zakrzewski, G. A. Voth, P. Salvador, J. J. Dannenberg, S. Dapprich, A. D. Daniels, Ö Farkas, J. B. Foresman, J. V. Ortiz, J. Cioslowski, and D. J. Fox, Gaussian, Inc., Wallingford CT, 2009.

[38] C. Cox, T. Lectka, J. Am. Chem. Soc. 120 (1998) 10660.

[39] S. Dokmaisrijan, V. Sanghiran Lee, P. Nimmanpipug, J. Mol. Struct. (Theochem) 953 (2010) 28 . 